\title{
НАШ ОПЫТ ВЕДЕНИЯ ПАЦИЕНТОВ С ГЕМОДИНАМИЧЕСКИ ЗНАЧИМЫМ ОТКРЫТЫМ АРТЕРИАЛЬНЫМ ПРОТОКОМ В СОЧЕТАНИИ С ВТОРИЧНЫМ ДЕФЕКТОМ МЕЖПРЕДСЕРДНОЙ ПЕРЕГОРОДКИ ПОГРАНИЧНЫХ РАЗМЕРОВ
}

\author{
${ }^{1}$ Куликова Д. А., \\ ${ }^{2}$ Сафонова И. Н., д. мед. н., профессор \\ ${ }^{3}$ Бучнева О. В. к. мед. н. \\ ${ }^{1}$ Украина, Харьков, врач - педиатр отделения кардиохирургии ГУ «Институт общей и \\ неотложной хирургии им. В.Т. Зайцева, Начиональной академии медичинских наук Украинь»» \\ ${ }^{2}$ кафедра лучевой диагностики Харьковская академия последипломного образования \\ заведующая отделением кардиохирургии ГУ «Институт общей и неотложной хирургии \\ им. В.Т. Зайцева, Национальной академии медицинских наук Украины»»
}

\section{DOI: https://doi.org/10.31435/rsglobal_ws/30082018/6062}

\section{ARTICLE INFO}

Received: 11 July 2018

Accepted: 28 August 2018

Published: 30 August 2018

\section{KEYWORDS}

congenital heart disease, PDA,

IIASD,

PFO,

hemodynamic significance.

\begin{abstract}
The article presents the experience of determining the type of surgical treatment with a combination of border-line PDA and IIASD. A multifactorial analysis of clinical, instrumental, and intraoperative data was carried out, and an integrated approach for the selection of a treatment strategy was defined. As a result of the performed study, reliable data of ultrasound examination for determination of hemodynamic predominance of one of the heart defects are presented.
\end{abstract}

Citation: Куликова Д. А., Сафонова И. Н., Бучнева О.В. (2018) Nash Opit Vedeniya Pacientov s Gemodinamicheski Znachimim Otkritim Arterialnim Protokom v Sochetanii s Vtorichnim Defektom Mejpredserdnoi Peregorodki Pogranichnih Razmerov. World Science. 8(36), Vol.2. doi: 10.31435/rsglobal_ws/30082018/6062

Copyright: () 2018 Куликова Д. А., Сафонова И. Н., Бучнева О. В. This is an open-access article distributed under the terms of the Creative Commons Attribution License (CC BY). The use, distribution or reproduction in other forums is permitted, provided the original author(s) or licensor are credited and that the original publication in this journal is cited, in accordance with accepted academic practice. No use, distribution or reproduction is permitted which does not comply with these terms.

Актуальность. Миниинвазивное лечение открытого артериального протока (ОАП) и вторичного дефекта межпредсердной перегородки (ДМПП) в последние годы постепенно вытесняет «классические» открытые хирургические методы лечения. При определении варианта оперативного лечения пациентов с врожденными пороками сердца (ВПС), в условиях страны с развивающейся экономикой, себестоимость интервенционных методов лечения выше стандартных открытых оперативных методов лечения. Так, к примеру, не всегда доступны или крайне ограниченны в таких условиях могут быть эндоваскулярные технологии [1].

Открытый артериальный проток и межпредсердное соустье являются физиологическими коммуникациями во внутриутробном периоде. В ближайшие часы после рождения в большинстве случаев они закрываются. По данным литературы сроки физиологического закрытия разнятся. Так, к примеру, физиологическим закрытием ОАП по мнению некоторых авторов, считается период от нескольких часов до 12 дней, а у недоношенных новорожденных до 8 недель после рождения. Частота встречаемости ОАП составляет приблизительно $10 \%$, а вторичного ДМПП от 6-10\% от врожденных пороков сердца. Функционирующее овальное окно 
(ФОО), в отличии от вторичного ДМПП, не относится к ВПС и может встречаться у 20-25\% здоровых людей. J Am Soc Echocardiogr 2015;28:910-58.) [2,3].

ФОО представляет собой элиптоидной или овальной формы незаращение между первичной и вторичной перегородками, расположенное в передневерхней части межпредсердной перегородки. Функциональное закрытие окна возможно до тех пор, пока давление в левом предсердии превышает давление в правом. При функционировании окно имеет вид «туннеля», так как первичная перегородка формирует флотирующий клапан. Иногда, окно может функционировать при перерастяжении лимбического тяжа вторичной перегородки вследствие дилатации предсердий, либо при аневризматически измененной первичной перегородке. Размер и частота встречаемости ФОО варьируют в различных возрастных группах. Частота встречаемости с возрастом уменьшается, а размер в среднем составляет около 5 мм. По правилам номенклатуры ФОО должно иметь право - левый сброс по данным цветового допплеровского исследования. При сочетании ФОО с состояниями, приводящими к перегрузке левого предсердия и увеличению диаметра окна, может наблюдаться лево - правый сброс. Такие случаи называют «растянутым» ФОО. К состояниям, приводящим к перегрузке левого предсердия относят митральный стеноз или недостаточность, а также открытый артериальный проток и другие пороки сердца $[4,5]$.

При наличии гемодинамически значимого ОАП первоначально увеличенный приток к левому предсердию приводит к перегрузке последнего, вызывая увеличение дефекта в области ФОО и, как следствие, появление лево - правого шунтирования $[6,7]$.

Вторичный ДМПП представляет собой дефект развития ткани межпредсердной перегородки в эмбриональном периоде. Это наиболее часто встречающийся тип ДМПП, который может быть представлен в виде овоидной или округлой формы, а также в виде множественных фенестраций в МПП, чаще в области овальной ямки. Размер вторичного ДМПП может увеличиваться с возрастом и ростом сердца и варьировать от нескольких миллиметров до 3 сантиметров [8, 9].

Трансторакальная визуализация межпредсердной перегородки не всегда позволяет дифференцировать «растянутое» ФОО от истинного вторичного дефекта. Открытый артериальный проток, как один из наиболее часто встречающихся ВПС, может сочетаться, как с ФОО, вызывая его растяжение вследствие перегрузки левого предсердия, так и с вторичным ДМПП. Тактика ведения этих групп пациентов принципиально различается, как объемом хирургического вмешательства, так и видом хирургического доступа. При применении открытой методики, необходимо выбирать оптимальный вид хирургического доступа, при котором удобства хирурга и минимизация послеоперационных осложнений сочетаются.

Перевязка ОАП производится без использования искусственного кровообращения, в отличие от вторичного ДМПП, что значительно менее травматично для пациента [10, 11$]$.

Согласно рекомендациям Американской Ассоциации кардиологов 2015г. можно применять чрезпищеводное исследование или проведение зондирования сердца, которые являются инвазивными процедурами и имеют свои риски [12].

Цель работы: определить гемодинамичекую значимость открытого артериального протока и вторичного дефекта межпредсердной перегородки при их сочетании с помощью ультразвукового обследования для выбора оптимальной тактики оперативного вмешательства.

\section{Материалы и методы.}

Проведен ретроспективный анализ историй болезни 165 детей с ОАП и вторичным ДМПП в различной комбинации гемодинамического преобладания одного из пороков без сопутствующих патологий. Все пациенты были обследованы и прооперированы на базе отделения кардиохирургии ГУ «ИОНХ им. В.Т. Зайцева НАМН Украины» за период 2013 - 2017 гг. Все пациенты обследовались по стандартной схеме, включавшей жалобы, сбор анамнеза, физикальное обследование, лабораторные исследования, рентгенографию органов грудной клетки, ЭКГ, эхокардиоскопию, при необходимости - зондирование сердца. У большинства детей отмечались частые простудные заболевания, в том числе бронхиты и пневмонии, задержка физического развития, одышка, шум в области сердца, признаки перегрузки камер сердца на ЭКГ и признаки гиперволемии малого круга при рентгенологическом исследовании. Ретроспективно по результатам оперативного лечения все пациенты были распределены на три группы по преобладанию одного из пороков. Все пациенты имели ОАП и ДМПП различного диаметра интраоперационно (ФОО и вторичный ДМПП). К 1-й группе были отнесены 58 пациентов с преобладанием ОАП и наличием ФОО. Предоперционно по данным ЭХО КС у всех детей данной группы по данным цветового допплеровского исследования (ЦДК) визуализировался ОАП, а из субкостальной позиции - ДМПП 
небольшого диаметра (1-3 мм) с лево - правым сбросом по данным ЦДК. 2-ю группу (51 ребенок) сформировали дети с ОАП с размером ДМПП из субкостальной позиции 4-7 мм., и лево - правым сбросом по дефекту. Последняя, 3-я группа представлена значимым ДМПП из субкостальной позиции в В режиме более 7 мм. с лево - правым шунтом по ЦДК и ОАП сомнительной визуализации - 56 детей.

Нами проведен анализ факторов, которые были распределены на несколько групп: анамнестические данные, клинико - инструментальные (не включающие ЭХО КС), эхокардиоскопические, периоперационные и особенности послеоперационного периода. По анамнестическим данным достоверных различий в исследуемых группах не выявлено, так как оба порока представляют собой состояние с обогащением малого круга кровообращения и имеют схожую клиническую картину. Среди клинико - инструментальных факторов были исследованы шум в области сердца, а также данные ЭКГ и рентгенографии органов грудной клетки.

Для пациентов 1-й группы при аускультации был больше характерен диастолический шум, преимущественно над легочной артерией $(87,9 \pm 4,3 \%)$, преобладание перегрузки левых камер сердца на ЭКГ $(53,4 \pm 6,6 \%)$ и признаки дилатации левых камер сердца по данным рентгенографии $91,4 \pm 3,7 \%$.

Для пациентов 2-й группы был характерен систоло - диастолический шум в области сердца при аускультации $(90,0 \pm 4,2 \%)$, признаки перегрузки как правых, так и левых камер сердца на ЭКГ $(51,0 \pm 7,1 \%$ и $49,0 \pm 7,1 \%)$. Дилатация правых отделов сердца на рентгенограмме $(56,9 \pm 7,0 \%)$ и левых $-43,1 \pm 7,0 \%$

Для пациентов 3-й группы был характерен систоло - диастолический шум в области сердца при аускультации $(96,4 \pm 2,5 \%)$, преобладание перегрузки правых камер сердца на ЭКГ $(62,5 \pm 6,5 \%)$ и дилатация правых отделов сердца на рентгенограмме $(92,9 \pm 3,5 \%)$.

К эхокардиоскопической группе были отнесены данные исследования в «В» режиме, ЦДК и постоянноволнового допплера. Для пациентов 1-й группы была характерна 100\% визуализация ОАП из парастернальной позиции по короткой оси в режиме ЦДК, что было основным критерием постановки диагноза. У $19,0 \pm 5,2 \%$ - визуализация ОАП из супрастернальной позиции в «В» режиме, у $29,3 \pm 6,0 \%$ визуализация ОАП из супрастернальной позиции в режиме ЦДК и у $19,0 \pm 5,2 \%$ визуализация ОАП из парастернальной позиции в «В» режиме. У $62,1 \pm 6,4 \%$ из них наблюдались признаки дилатации легочной артерии, как следствие гиперволемии. У $75,9 \pm 5,7 \%$ - признаки дилатации левой ветки легочной артерии, как наиболее частой локализации впадения ОАП. У $91,4 \pm 3,7 \%$ - признаки дилатации левого предсердия, вследствие увеличения Qp/Qs, а также $60,3 \pm 6,5 \%$ - признаки дилатации левого желудочка. У $87,9 \pm 4,3 \%$ - повышение градиента на легочной артерии более 13 мм.рт.ст., также как следствие гиперволемии (среднее значение этого показателя в данной группе - 17,98 мм. рт. ст.). Минимальный вторичный ДМПП диагностирован из субкостальной позиции по данным ЭХО КС в режиме 2D и ЦДК. Диаметр вторичного ДМПП варьировал от минимального лево правого шунтирования только в режиме цветового допплера до 3 мм перерыва сигнала в МПП по данным 2D режима в сочетании с лево - правым сбросом по ЦДК.

Для детей, входящих во 2-ю группу также была характерна 100\% визуализация ОАП из парастернальной позиции по короткой оси в режиме ЦДК. У основной части детей диагностирована дилатация легочной артерии и ее левой ветки - 84,3 $\pm 5,1 \%$ и $82,4 \pm 5,4 \%$ соответственно. Также в большинстве случаев наблюдалась дилатация правого предсердия $94,1 \pm 3,3 \%$ и лишь у $5,9 \pm 3,3 \%$ отмечена дилатация левого предсердия. У $51,0 \pm 7,1 \%$ дилатация правого желудочка. У $84,3 \pm 5,1 \%$ детей визуализирован ДМПП в серошкальном режиме из субкостальной позиции. 70,6 $6,4 \%$ пациентов данной группы имели повышение градиента на легочной артерии 13 мм. рт. ст. Среднее значение этого показателя в данной группе 15,67 мм. рт. ст.

Для 3-й группы пациентов характерна 100\% визуализация ДМПП в серошкальном режиме из субкостальной позиции, а визуализация ОАП из парастернальной позиции по короткой оси в режиме ЦДК и визуализация ОАП из супрастернальной позиции в режиме ЦДК отмечена лишь у $30,4 \pm 6,2 \%$ и $19,6 \pm 5,4 \%$ пациентов соответственно. У всех детей данной группы визуализация ОАП из парастернальной позиции в «В» режиме была невозможна, а визуализация ОАП из супрастернальной позиции в «В» режиме отмечалась лишь у $3,6 \%$ пациентов этой группы. У $80,4 \pm 5,4 \%$ из них наблюдались признаки дилатации легочной

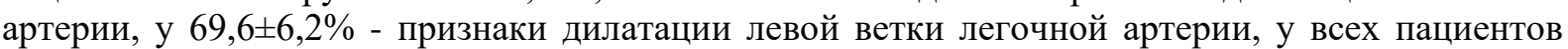
были признаки дилатации правого предсердия и у $89,3 \pm 4,2 \%$ - признаки дилатации правого 
желудочка. У $87,5 \pm 4,5 \%$ - повышение градиента на легочной артерии более 13 мм. рт. ст. Среднее значение этого показателя в данной группе - 18,04 мм. рт. ст.

Визуализация вторичного дефекта проводилась из субкостальной позиции, из четырехкамерной апикальной позиции и парастернальной позиции по короткой оси. Размер вторичного дефекта был значительным, перерыв ЭХО сигнала в серошкальном режиме был от 8 мм. и сопровождался лево - правым шунтированием в режиме ЦДК.

Для определения гемодинамической значимости ОАП по данным ультразвукового обследования использовался разработанный нами метод определения соотношения площади сброса по ОАП к площади легочной артерии. Измерения проводились из стандартной парастернальной позиции по короткой оси с максимальной визуализацией легочной артерии, включая клапан, ствол и две ветви. В режиме ЦДК определялся сброс по ОАП с максимальной визуализацией потока струи и диаметра ее основания. Измерение площади струи проводилось путем обведения потока. Затем измерялась площадь визуализированного участка легочной артерии. Эти площади сравнивались в процентном соотношении. При незначительном сбросе площадь потока была менее $20 \%$ от площади всей видимой легочной артерии, при более значимом сбросе площадь потока составляла от 20-40\% площади легочной артерии и, соответственно, при значимом сбросе по ОАП - более $40 \%$. Соответственно, гемодинамически не значимым считался ОАП при площади потока менее $20 \%$, пограничная гемодинамическая значимость ОАП соответствовала площади потока от 20 до 40\% и гемодинамически значимым ОАП считался при площади потока более $40 \%$. Для каждой группы пациентов была посчитана величина площади сброса. Так дети 1-й группы имели преимущественно гемодинамически значимый ОАП - 77,6 $\pm 5,5 \%$ и лишь $22,4 \pm 5,5 \%$ имели погранично гемодинамически значимый сброс, который соответствовал площади потока от $20-40 \%$. У $76,5 \pm 6,0 \%$ детей 2-й группы преобладала пограничная гемодинамическая значимость ОАП, соответствующая площади

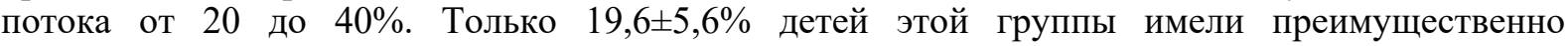
гемодинамически значимый ОАП и лишь $3,9 \pm 2,7 \%$ - незначительный. У детей 3 -й группы преобладал незначительный сброс площади потока, т.е. у 78,6 $55,5 \%$ из них эта величина была менее $20 \%$ от площади всей видимой легочной артерии, $19,6 \pm 5,4 \%$ из них имели погранично гемодинамически значимый сброс и менее $2 \%$ - гемодинамически значимый. В таблице 1 поданы диагностические критерии, что были использованы для определения тактики оперативного вмешательства у данных групп детей.

Исследованные нами периоперационные факторы подразумевали: вид хирургического доступа, интраоперационные данные, а также особенности раннего послеоперационного периода: время экстубации, время перевода из палаты интенсивной терапии и наличие респираторных осложнений в течение 7 суток после операции. Удобство оперативного доступа в значительной мере способствует удачному результату хирургического вмешательства. Так, при перевязке ОАП стандартно был использован хирургический доступ из левосторонней торакотомии. В условиях сочетания значимого ДМПП с ОАП методом выбора хирургического доступа была стернотомия. В условиях отсутствия данных в пользу ОАП до оперативного лечения, хирургами отдавалось предпочтение правосторонней торакотомии, что затрудняло перевязку ОАП при его обнаружении интраоперационно.

Дети из 1-й группы все были прооперированы с использованием левостороннего торакотомного доступа. Интраоперационно гемодинамическая значимость ОАП верифицирована по следующим критериям: визуализация ОАП (наружный диаметр), после перевязки - подъемом системного давления на 10-15 мм. рт. ст., улучшением пульсации в области нисходящей аорты и нижних конечностей.

Пациенты были экстубированы в среднем через 40 минут после окончания операции. $79,3 \pm 5,4 \%$ из них были переведены из палаты интенсивной терапии (ПИТ) уже в течении 1-х суток после операции и $94,8 \pm 2,9 \%$ детей не имели респираторных осложнений в течение 7 суток после операции, что ускорило процесс выздоровления и реабилитации.

Стернотомный доступ при оперативном вмешательстве использовался для детей с предоперационным диагнозом сочетания вторичного ДМПП и ОАП. Однако, у части пациентов интраоперационные данные не совпали с предоперационным диагнозом. Так, у пациентов 3-й группы у $80,4 \pm 5,4 \%$ ОАП был диагностирован до оперативного лечения. Эти пациенты были успешно прооперированы с использованием стернотомного доступа.

У $19,6 \pm 5,4 \%$ пациентов 3-й группы ОАП был интраоперационной находкой. Для таких детей использовали правосторонний торакотомный доступ, менее травматичный для коррекции ДМПП. В результате обнаружение ОАП в ходе операции создавало значительные неудобства, 
что негативно сказывалось на состоянии пациентов, течении послеоперационного периода и дальнейшего выздоровления.

Таблица 1. Диагностические критерии для определения тактики лечения пациентов с врожденными пороками сердца (ОАП и ДМПП), использованые в исследовании.

\begin{tabular}{|c|c|c|c|c|c|c|}
\hline \multirow[t]{2}{*}{ Диагностические критерии } & \multicolumn{2}{|c|}{$\begin{array}{c}\text { 1-я группа (OAП) } \\
\text { Всего } 58\end{array}$} & \multicolumn{2}{|c|}{$\begin{array}{c}\text { 2-я группа } \\
\text { (ОАП и ДМПП) } \\
\text { Всего } 51 \\
\end{array}$} & \multicolumn{2}{|c|}{$\begin{array}{c}\text { 3-я группа } \\
\text { (ДМПП) } \\
\text { Всего } 56\end{array}$} \\
\hline & Абс. & $\mathrm{P} \pm \mathrm{m}(\%)$ & Абс. & $\mathrm{P} \pm \mathrm{m}(\%)$ & Абс. & $\mathrm{P} \pm \mathrm{m}(\%)$ \\
\hline $\begin{array}{l}\text { Наличие признаков } \\
\text { перегрузки левых камер на } \\
\text { ЭКГ }\end{array}$ & 31 & $53,4 \pm 6,6$ & 25 & $49,0 \pm 7,1$ & 21 & $37,5 \pm 6,5$ \\
\hline $\begin{array}{l}\text { Наличие признаков } \\
\text { перегрузки правых камер по } \\
\text { ЭКГ }\end{array}$ & 27 & $46,6 \pm 6,6$ & 26 & $51,0 \pm 7,1$ & 35 & $62,5 \pm 6,5$ \\
\hline $\begin{array}{l}\text { Наличие дилатации левых } \\
\text { отделов сердца на } \\
\text { рентгенограмме }\end{array}$ & 53 & $91,4 \pm 3,7$ & 22 & $43,1 \pm 7,0$ & 4 & $7,1 \pm 3,5$ \\
\hline $\begin{array}{l}\text { Наличие дилатации правых } \\
\text { отделов сердца на } \\
\text { рентгенограмме }\end{array}$ & 5 & $8,6 \pm 3,7$ & 29 & $56,9 \pm 7,0$ & 52 & $92,9 \pm 3,5$ \\
\hline $\begin{array}{l}\text { Шум в области сердца при } \\
\text { аускультации }\end{array}$ & 51 & $87,9 \pm 4,3$ & 46 & $90,0 \pm 4,2$ & 54 & $96,4 \pm 2,5$ \\
\hline УЗИ данные & & & & & & \\
\hline $\begin{array}{l}\text { Визуализация ОАП из } \\
\text { парастернальной позиции по } \\
\text { короткой оси в режиме ЦДК }\end{array}$ & 58 & $100 \%$ & 51 & $100 \%$ & 17 & $30,4 \pm 6,2$ \\
\hline $\begin{array}{l}\text { Отсутствие визуализации } \\
\text { ОАП из парастернальной } \\
\text { позиции в В режиме }\end{array}$ & 47 & $81,0 \pm 5,2$ & 44 & $86,3 \pm 4,9$ & 56 & $100 \%$ \\
\hline $\begin{array}{l}\text { Отсутствие визуализации } \\
\text { ОАП из супрастернальной } \\
\text { позиции в режиме ЦДК }\end{array}$ & 41 & $70,7 \pm 6,0$ & 37 & $72,5 \pm 6,3$ & 45 & $80,4 \pm 5,4$ \\
\hline $\begin{array}{l}\text { Отсутствие визуализации } \\
\text { ОАП из супрастернальной } \\
\text { позиции в В режиме }\end{array}$ & 30 & $51,7 \pm 6,6$ & 43 & $84,3 \pm 5,1$ & 54 & $96,4 \pm 2,5$ \\
\hline $\begin{array}{l}\text { Площадь сброса по ОАП) } \\
0-20 \% \\
21-40 \% \\
41 \% \text { и более }\end{array}$ & $\begin{array}{c}0 \\
13 \\
45 \\
\end{array}$ & $\begin{array}{l}0 \\
22,4 \pm 5,5 \\
77,6 \pm 5,5\end{array}$ & $\begin{array}{c}2 \\
39 \\
10 \\
\end{array}$ & $\begin{array}{l}3,9 \pm 2,7 \\
76,5 \pm 6,0 \\
19,6 \pm 5,6 \\
\end{array}$ & $\begin{array}{c}44 \\
11 \\
1 \\
\end{array}$ & $\begin{array}{l}78,6 \pm 5,5 \\
19,6 \pm 5,4 \\
1,8 \pm 1,8 \\
\end{array}$ \\
\hline Дилатация легочной артерии & 36 & $62,1 \pm 6,4$ & 43 & $84,3 \pm 5,1$ & 45 & $80,4 \pm 5,4$ \\
\hline $\begin{array}{l}\text { Дилатация левой ветки } \\
\text { легочной артерии }\end{array}$ & 44 & $75,9 \pm 5,7$ & 42 & $82,4 \pm 5,4$ & 39 & $69,6 \pm 6,2$ \\
\hline $\begin{array}{l}\text { Повышение градиента на } \\
\text { легочной артерии } \\
\text { до } 12 \text { мм. рт. ст. } \\
\text { 13мм.рт.ст. и более }\end{array}$ & $\begin{array}{c}7 \\
51\end{array}$ & $\begin{array}{l}12,1 \pm 4,3 \\
87,9 \pm 4,3\end{array}$ & $\begin{array}{l}15 \\
36\end{array}$ & $\begin{array}{l}29,4 \pm 6,4 \\
70,6 \pm 6,4\end{array}$ & $\begin{array}{c}7 \\
49 \\
\end{array}$ & $\begin{array}{l}12,5 \pm 4,5 \\
87,5 \pm 4,5\end{array}$ \\
\hline Дилатация левого предсердия & 53 & $91,4 \pm 3,7$ & 13 & $25,5 \pm 6,2$ & 10 & $17,9 \pm 5,2$ \\
\hline Дилатация левого желудочка & 35 & $60,3 \pm 6,5$ & 16 & $31,4 \pm 6,6$ & 8 & $14,3 \pm 4,7$ \\
\hline $\begin{array}{l}\text { Дилатация правого } \\
\text { предсердия }\end{array}$ & 12 & $20,7 \pm 5,4$ & 48 & $94,1 \pm 3,3$ & 56 & 100 \\
\hline Дилатация правого желудочка & 11 & $19,0 \pm 5,2$ & 26 & $51,0 \pm 7,1$ & 50 & $89,3 \pm 4,2$ \\
\hline $\begin{array}{l}\text { Отсутствие повышения } \\
\text { градиента в области } \\
\text { нисходящей аорты }\end{array}$ & 46 & $79,3 \pm 5,4$ & 38 & $74,5 \pm 6,2$ & 52 & $92,9 \pm 3,5$ \\
\hline $\begin{array}{l}\text { Визуализация ДМПП в } \\
\text { серошкальном режиме из } \\
\text { субкостальной позиции }\end{array}$ & 6 & $10,3 \pm 4,0$ & 43 & $84,3 \pm 5,1$ & 56 & 100 \\
\hline
\end{tabular}


По завершению операции дети были экстубированы в среднем через 3-3,5 часа после ее окончания. В течении 1-х суток после операции $98,2 \pm 1,8 \%$ пациентов были переведены в обычную палату. В течение первых 7 суток после операции более половины детей $(51,8 \pm 6,7 \%)$ имели респираторные осложнения.

Последняя группа факторов представлена данными послеоперационного периода: ультразвуковое обследование, наличие респираторных проблем в течение года и наличием осложнений со стороны послеоперационного рубца и грудины. Ультразвуковое обследование всем пациентам проводилось через 7 дней, 1 месяц, 6 месяцев и 1 год после оперативного лечения.

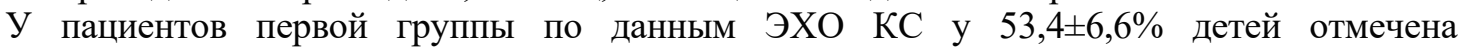
нормализация камер сердца и закрытие ДМПП на 7 день после операции. К 30-му дню послеоперационного периода у $27,6 \pm 5,9 \%$ детей диагностирована нормализация камер сердца и у $20,7 \pm 5,4 \%$ закрытие ДМПП, а $17,2 \pm 5,0 \%$ детей имели нормальные камеры и сердца и $20,7 \pm 5,4 \%$ закрытие ДМПП через 6 месяцев после операции соответственно. Остальные выздоравливали в

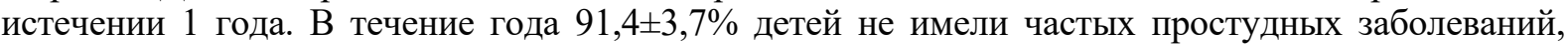
никто не имел осложнений со стороны грудины, т.к. при операции использовался торакотомный доступ и $87,9 \pm 4,3 \%$ не имели эстетических проблем в области рубца.

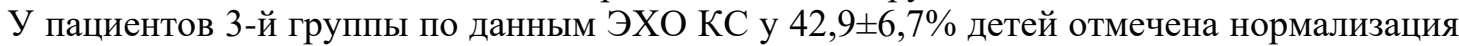
камер сердца на 7 день после операции и у 41,1土6,6\% к 30-му дню послеоперационного

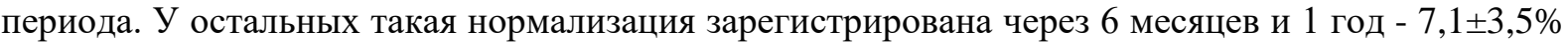
и $8,9 \pm 3,8 \%$ соответственно. Динамика закрытия ДМПП в данной группе не изучалась, т.к. указанный дефект был устранен в ходе операции. В течение года $83,9 \pm 5,0 \%$ детей не имели частых простудных заболеваний, но более половины прооперированных $(58,9 \pm 6,6 \%)$ имели осложнения со стороны грудины и эстетические проблемы в области рубца, что связано с развитием аутоиммунных механизмов как ответной реакции на применение методики искусственного кровообращения.

Вторая группа представлена пациентами с гемодинамически значимыми ОАП в сочетании с вторичным ДМПП пограничных размеров (с диаметром 4-6 мм. в «В» режиме и лево - правым сбросом по ЦДК). Особенностью пациентов данной группы было наличие дилатаций правых отделов сердца, что послужило диагностической переоценкой гемодинамической значимости вторичного ДМПП. Эту группу пациентов мы разделили на две подргуппы: А тактика ведения с акцентом в сторону коррекции преобладающего ДМПП 18 человек и группа Б - тактика ведения по преобладанию ОАП - 33 человек. В подгруппе 2А было отдано предпочтение гемодинамической значимости ДМПП, так как у данной группы пациентов

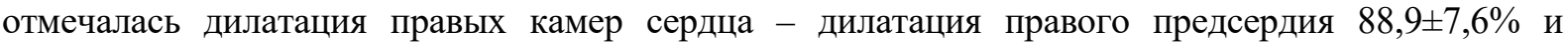
дилатация правого желудочка $55,6 \pm 12,1 \%$, что приято считать более характерным для вторичного ДМПП, чем для ОАП. В этой группе преобладала пограничная гемодинамическая значимость ОАП, соответствующая площади потока от 20 до 40\% легочной артерии - 83,3 $99,0 \%$. Такие дети были прооперированы при помощи стернотомного доступа. Ретроспективно было отмечено, что у пациентов данной группы интраоперационно отмечалось преобладание гемодинамической значимости ОАП, а при ревизии ДМПП в условиях ИК диаметр дефекта был незначительным, зачастую переоцененный по данным ультразвукового исследования. Таким образом, было принято решение таких пациентов переориентировать в группу с гемодинамическим преобладанием ОАП. Результаты анализа данных обследования и хирургического лечения пациентов подгруппы $2 \mathrm{~A}$ послужили основой тактики, примененной при лечении пациентов подгруппы 2Б. У пациентов подгруппы 2Б также отмечалась дилатация правых камер сердца дилатация правого предсердия 97,0 $3,0 \%$ и дилатация правого желудочка $51,5 \pm 8,8 \%$, а также преобладали показатели пограничной гемодинамической значимости ОАП, соответствующие

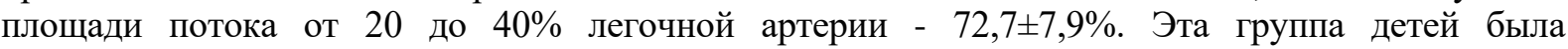
прооперирована с использованием левостороннего торакотомного доступа, менее травматизирующего, чем стернотомный и в ходе операции было выявлено преобладание гемодинамической значимости ОАП. Особенности послеоперационного периода детей обеих подгрупп для сравнения поданы в таблице 2. 
Таблица 2. Особенности послеоперационного периода у пациентов исследуемых групп

\begin{tabular}{|c|c|c|c|c|c|c|}
\hline \multirow[t]{2}{*}{$\begin{array}{c}\text { Диагностические } \\
\text { критерии }\end{array}$} & \multicolumn{2}{|c|}{$\begin{array}{c}\text { 2А подгруппа } \\
\text { Всего } 18 \text { человек }\end{array}$} & \multicolumn{2}{|c|}{$\begin{array}{c}\text { 2-Б подгруппа } \\
\text { Всего } 33 \text { человека }\end{array}$} & \multirow{2}{*}{$\begin{array}{c}\text { Значение } \\
\text { критерия } \\
\chi^{2}-\text {-ирсона }\end{array}$} & \multirow{2}{*}{$\begin{array}{c}\text { Уровень } \\
\text { статисти- } \\
\text { ческой } \\
\text { значимости } \\
\end{array}$} \\
\hline & Абс. & $\mathrm{P} \pm \mathrm{m}(\%)$ & Абс. & $\mathrm{P} \pm \mathrm{m}(\%)$ & & \\
\hline $\begin{array}{l}\text { Время перевода } \\
\text { из ПИТ } \\
\text { - в течении 1-х } \\
\text { суток после } \\
\text { операции } \\
\text { - на 2-е сутки } \\
\text { после операции }\end{array}$ & $\begin{array}{c}0 \\
18\end{array}$ & $\begin{array}{c}0 \\
100\end{array}$ & $\begin{array}{c}27 \\
6\end{array}$ & $\begin{array}{l}81,8 \pm 6,8 \\
18,2 \pm 6,8\end{array}$ & 31,295 & $\mathrm{p}<0,05$ \\
\hline $\begin{array}{l}\text { Отсутствие } \\
\text { респираторных } \\
\text { осложнений в } \\
\text { течение } 7 \text { суток } \\
\text { после } \\
\text { оперативного } \\
\text { лечения }\end{array}$ & 9 & $50,0 \pm 12,1$ & 28 & $84,8 \pm 6,3$ & 7,102 & $\mathrm{p}<0,05$ \\
\hline $\begin{array}{l}\text { Нормализация } \\
\text { камер сердца } \\
\text { - в течении 1-го } \\
\text { месяца после } \\
\text { операции } \\
\text { - в течении 2-6 } \\
\text { месяцев после } \\
\text { операции }\end{array}$ & $\begin{array}{c}14 \\
4\end{array}$ & $\begin{array}{l}77,8 \pm 10,1 \\
22,2 \pm 10,1\end{array}$ & $\begin{array}{l}18 \\
15\end{array}$ & $\begin{array}{l}54,5 \pm 8,8 \\
45,5 \pm 8,8\end{array}$ & 2,689 & $\mathrm{p}>0,05$ \\
\hline $\begin{array}{l}\text { Отсутствие } \\
\text { частых } \\
\text { респираторных } \\
\text { заболеваний в } \\
\text { отдаленном } \\
\text { послеоперационн } \\
\text { ом периоде }\end{array}$ & 14 & $77,8 \pm 10,1$ & 29 & $87,9 \pm 5,8$ & 0,899 & $\mathrm{p}>0,05$ \\
\hline $\begin{array}{l}\text { Отсутствие } \\
\text { осложнений со } \\
\text { стороны грудины }\end{array}$ & 12 & $66,7 \pm 11,4$ & 32 & $97,0 \pm 3,0$ & 9,03 & $\mathrm{p}<0,05$ \\
\hline $\begin{array}{l}\text { Эстетические } \\
\text { проблемы в } \\
\text { области рубца }\end{array}$ & 17 & $94,4 \pm 5,6$ & 0 & 0 & - & - \\
\hline
\end{tabular}

Так дети, прооперированные стернотомным доступом (группа 2А) были переведены из ПИТ только на 2-е сутки, в то время как $81,8 \pm 6,8 \%$ детей из группы 2 Б, прооперированных с использованием левостороннего торакотомного доступа было переведено из ПИТ на 1-сутки после операции $(\mathrm{p}<0,05)$. Отсутствие респираторных осложнений в течение 7 суток посте операции отмечено у $84,8 \pm 6,3 \%$ детей 2Б группы в сравнении с $50,0 \pm 12,1 \%$ в 2 А группе $(\mathrm{p}<0,05)$. Также высокий уровень статистической значимости $(\mathrm{p}<0,05)$ выявлен по критерию отсутствия осложнений со стороны грудины в исследуемых группах, что было ожидаемым.

\section{Выводы.}

1. Для определения тактики оперативного лечения в условиях сочетанной патологии ОАП и вторичного ДМПП необходим комплексный подход с применением многофакторного анализа.

2. Выбор оптимального доступа при оперативном лечении играет очень важную роль для благоприятного прогноза.

3. Наличие дилатации правых камер сердца при сочетании ОАП и вторичный ДМПП далеко не всегда является предиктором гемодинамического преобладания дефекта. 
4. Разработанный метод определения при помощи ультразвука гемодинамической значимости ОАП при помощи определения соотношения площади сброса по ОАП к площади легочной артерии может быть использован как один из основных диагностический критерий.

5. Выбор объема оперативного лечения зависит от правильности дифференциальной диагностики гемодинамической значимости отдельных пороков при их комбинации.

6. При наличии гемодинамически значимого ДМПП визуализация ОАП при помощи ультразвука остается затруднительной и требует дальнейшего исследования. В случае необходимости проведения оперативного лечения из торакотомного доступа рекомендуется проведение дополнительных методов исследования.

\section{ЛИТЕРАТУРА}

1. Reliability of Echocardiography Measurement of Patent Ductus Arteriosus Minimum Diameter: A Metaanalysis / Yong-quan Huang, Yin Huang, Dan Huang // International Journal of Cardiovascular and Cerebrovascular Disease. - 2016. - №. 4(2). - P.15-19.

2. Surgical treatment of patent ductus arteriosus: A new historical perspective/ H. Kaemmerer, H. Meisner, J. Hess, [et al.] // Am. J.Cardiol. - 2004. - Vol. - 94. - P. 1153-1154.

3. Критерії діагностики гемодинамічно значущої відкритої артеріальної протоки у недоношених новонароджених / Бойченко А. Д., Гончарь М. О., Кондратова І. Ю. [та ін.] // Неонатологія, хірургія та перинатальна медицина. - 2015. - №. 1 (5). - Т. VC. $24-27$.

4. Прийма Н. Ф. Эхокардиографическое исследование в дифференциальной диагностике открытого артериального протока у детей / Н. Ф. Прийма, В. В. Попов, Д. О. Иванов // Педиатр. - 2016. - Т. 7. - Вып. - 4. - С. 119-127.

5. Гемодинамічно значуща відкрита артеріальна протока у недоношених новонароджених. Проблема чи ні? / Г. С. Сенаторова, А. Д. Бойченко, М. О. Гончарь [та ін.] // Международный журнал педиатрии, акушерства и гинекологии. - 2015. - Т. 8. - №. 1. - С. 87.

6. Жарінов О. Й. Функціональна діагностика / О. Й. Жарінов, Ю. А. Іванів, В.О. Куць. - Кийв: Четверта хвиля, 2018. - С. 493-504.

7. Павлюк В. І. Практична єхокардіографія / В. І. Павлюк. - Львів. - 2014. - С. $72-85$.

8. Khalil A. Essentials of Pediatric Cardiology / A. Khalil // Jaypee LTD. - 2011. - 414 p.

9. D'Alessandro P. Perinatal management of congenital heart disease in Nova Scotia: a 20 year retrospective on survival and outcomes / P. D’Alessandro, K. Jangaard // J. Perinat. Med. - 2013. - №. 41. - P. 153.

10. Guidelines for the Echocardiographic Assessment of Atrial Septal Defect and Patent Foramen Ovale: From the American Society of Echocardiography and Society for Cardiac Angiography and Interventions Frank E. Silvestry, MD, FASE, Chair, Meryl S. Cohen, MD, FASE, Co-Chair, Laurie B. Armsby, MD, FSCAI, Nitin J. Burkule, MD, DM, FASE, Craig E. Fleishman, MD, FASE, Ziyad M. Hijazi, MD, MPH, MSCAI, Roberto M. Lang, MD, FASE, Jonathan J. Rome, MD, and Yan Wang, RDCS, Philadelphia, Pennsylvania; J Am Soc Echocardiogr. - 2015. - №28. - P. 910-958.

11. Hasan Asif. Patent Foramen Ovale - Clinical Significance. /Asif Hasan, Anjum Parvez, MR Ajmal // JIACM. - 2004. - №5(4). - P. 339-344.

12. Shelby Kutty. Patent Foramen Ovale. The Known and the To Be Known / Kutty Shelby, Partho P. Sengupta, Bijoy K. Khandheria // Journal of the American College of Cardiology Vol.59. - No.19. - 2012. Inc. doi:10.1016/j.jacc.2011.09.085. 